\title{
EXPERIMENTAL INVESTIGATION OF THE INFLUENCE OF SUPPLY TEMPERATURE AND SUPPLY PRESSURE ON THE PERFORMANCE OF A TWO AXIAL GROOVE HYDRODYNAMIC JOURNAL BEARING
}

\author{
F.P. Brito, A.S. Miranda \\ University of Minho, Mechanical Engineering Department, \\ 4810 Guimarães, Portugal
}

\author{
J. Bouyer, and M. Fillon \\ University of Poitiers, Laboratoire de Mécanique des Solides, U.M.R. \\ C.N.R.S. 6610, SP2MI, BP 30179, 86962 Futuroscope cedex, France
}

\begin{abstract}
An experimental study of the influence of oil supply temperature and supply pressure on the performance of a $100 \mathrm{~mm}$ plain journal bearing with two axial grooves located at $\pm 90^{\circ}$ to the load line was carried out. The hydrodynamic pressure at the mid-plane of the bearing, temperature profiles at the oil-bush and oil-shaft interfaces, bush torque, oil flow rate, and the position of the shaft were measured for variable operating conditions. Shaft rotational speed ranged from 1000 to 4000rpm and two different values of applied load were tested $(2 \mathrm{kN}$ and $10 \mathrm{kN})$. The supply temperature ranged from 35 to $50^{\circ} \mathrm{C}$, whereas the oil supply pressure range was $70 \mathrm{kPa}$ to $210 \mathrm{kPa}$.

Bearing performance is strongly dependent on the supply conditions. It was found that the existence of the downstream groove significantly affects the temperature profile at the oilbush interface except for the low load, low feeding pressure cases, where the cooling effect of the upstream groove is significant. Feeding temperature has a strong effect on the minimum film thickness. The increase in maximum temperature is significantly lower than the corresponding increase in supply temperature. Increases in supply pressure lead to a significant rise in oil flow rate but have little effect on the maximum temperature and power-loss, except in the case of the lightly-loaded bearing. Shaft temperature was found to be close to the bearing maximum temperature for low applied loads, being significantly smaller than this value for high loads. The mean shaft temperature is only significantly higher than the outlet temperature at high shaft speeds.
\end{abstract}

\section{INTRODUCTION}

Hydrodynamic journal bearings are widely used in mechanical systems, being the only practical option in cases where shafts are subjected to high velocities and high applied loads. Under such conditions, thermal effects become a major factor in the bearing performance. The generation of large amounts of heat by viscous dissipation brings about a significant temperature increase in the lubricant film. This causes a drop in oil viscosity and thus a reduction in load capacity. It is thus vital to fully understand and take into account thermal effects if bearing performance predictions are to be improved and system seizure under severe operating conditions is to be prevented.

The lubricant supply conditions greatly affect bearing performance. In particular feeding temperature and pressure have a vital role in the resulting temperature field in the bearing.

Experimental investigations on hydrodynamic journal bearings have been carried out over several decades. The study of the influence of oil supply conditions has been undertaken by several authors, especially in relation to single groove plain journal bearings. Here, it is worth mentioning the work of Dowson et al. [1], who studied the effect of the supply temperature on the bearing temperature distribution. Majumdar and Saha [2], using a journal bearing with a single axial groove located at the position of maximum film thickness, analyzed the effect of supply pressure on the bush temperature distribution. Mitsui et al. [3], varying the supply temperature and the oil thermoviscosity, analyzed the cooling effect of the supply oil on a single axial groove plain journal bearing. Syverud and Tanaka [4] also studied the effect of feed temperature by using a system to heat and cool the shaft in order to study the heat transfer mechanisms inside the bearing. Finally, Costa et al. [5] investigated the influence of the supply conditions, including groove length and location, on bearing performance.

Experimental work concerning two axially grooved journal bearings is scarcer. The existence of an additional groove dramatically affects the flow patterns and the temperature field inside the bearing. Difficulties in theoretical modeling arise in flow and temperature calculations, especially near the grooves. Nevertheless, these bearings have a higher load capacity than variable geometry (tilting pad) bearings, being suitable for 
steady-regime operation. They permit the rotation of the shaft in both directions. The inclusion of the downstream groove permits them to work at a lower temperature than in the case of single groove bearings. The work of Lund and Tonnesen [6] is often referred to as it is one of the first well documented experimental work focusing on temperature measurements for this type of bearing. However, the scope of this work did not encompass the study of the supply conditions. Claro [7] carried out a parametric study on the influence of the supply conditions, which also included this bearing geometry, in order to validate an isothermal model for bearing performance analysis. This work was not focused on thermal measurements. Gethin and El-Deihi [8] studied the effect of the groove location on the performance of two axial groove bearings. They concluded that small changes in the groove location can cause significant changes in the pressure and temperature. Fitzgerald and Neal [9] provide results for the temperature fields at the shaft and bush surfaces for various rotational speeds and applied loads, using fixed supply conditions. Finally, Ma and Taylor [10] carried out a series of tests with two grooved elliptical bearings to assess the influence of feeding temperature and pressure on bearing performance.

In relation to studies of the influence of oil supply pressure and supply temperature in 2-grooved journal bearings, the experimental data available is clearly scarce. The aim of the present work is to address this lack of experimental data in order to ensure a better understanding of the influence of supply conditions on bearing performance. Current theoretical models still do not give good estimates of the temperature evolution at the unloaded lobe of the bearing. It is anticipated that a better understanding of the combined effect of the two grooves on the temperature field will improve theoretical modeling, thereby allowing better predictions to be made about the thermal behavior of bearings.

\section{BEARING TEST RIG AND EXPERIMENTAL PROCEDURE}

Figure 1 shows the test rig of the LMS-Poitiers. This rig has been used for a good deal of experimental work, from the study of thermal effects in journal bearings by Ferron, Frêne and Boncompain [11] to the recent study of the effect of misalignment on the performance of journal bearings by Bouyer and Fillon [12]. A description of the experimental layout has previously been presented in these studies. Thus, only a brief description is necessary here.

The equipment allows the operating conditions (rotational speed and applied load) to be controlled, as well as the supply conditions (oil supply pressure and temperature). The measured parameters were the following: oil flow rate, temperature fields at the oil-bush and oil-shaft interfaces, oil outlet temperature, bush body temperature at different locations, position of shaft center relative to the bush center, hydrodynamic pressure along the mid-plane of the inner surface of the bush, and bush torque.

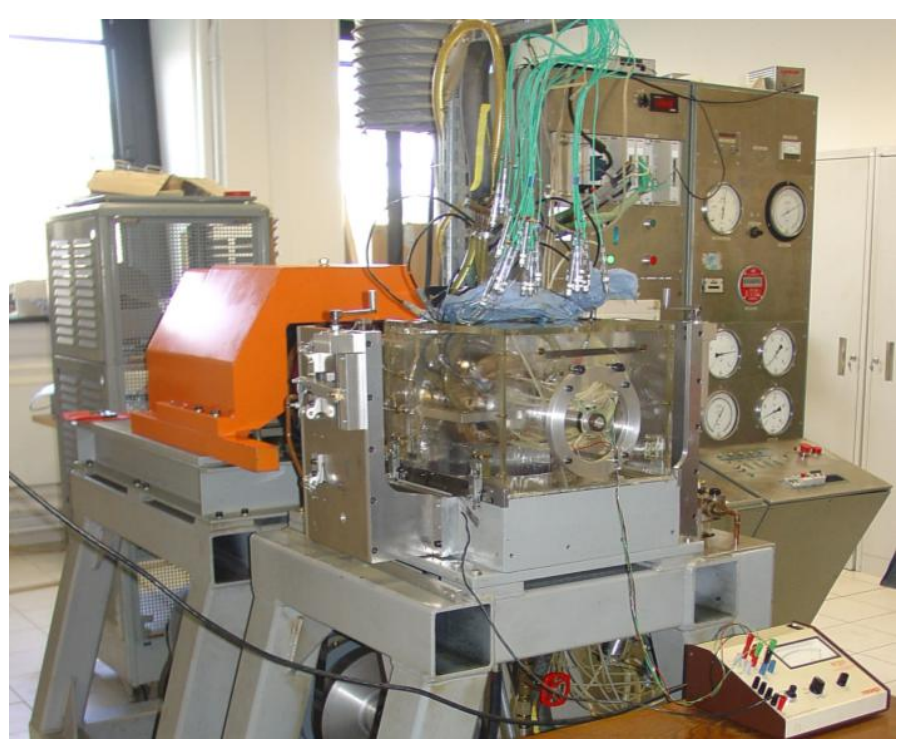

Fig. 1 - Test rig

The shaft is driven by a $21 \mathrm{~kW}$ variable speed DC motor via a transmission belt. The speed is regulated with an accuracy of $\pm 5 \mathrm{rpm}$, by an electronic controller connected to the data acquisition and control system. The shaft is supported by three precision preloaded rolling bearings that provide a stable and stiff mode of operation for the whole system.

The inner part of the bush, depicted in Fig. 2, is built of bronze and is designed to be inserted in a pre-existent sleeve whose purpose is to permit the testing of different bush geometries in the same experimental machine. The shaft is made of 100C6 steel. The diametral clearance is $171 \pm 5 \mu \mathrm{m}$ $\left(20^{\circ} \mathrm{C}\right)$.

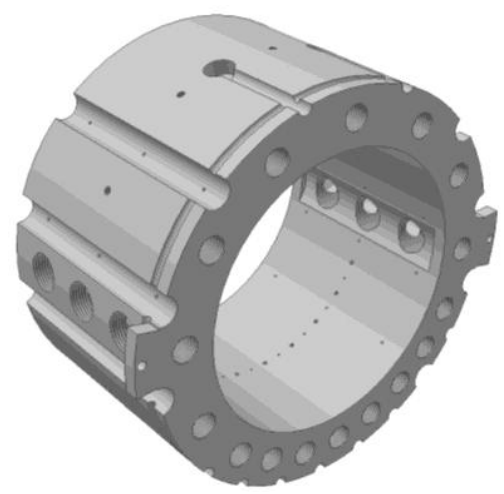

Fig. 2-3D drawing of the inner part of the bush

The loading system relies on a pneumatic cylinder that acts on the bearing sleeve. The load is applied to the bush along the vertical direction with an error of $\pm 0.2 \mathrm{kN}$. Between the loading system and the bearing there is a spherical hydrostatic bearing as well as a flat one. These ensure that a perfectly aligned load is applied to the bush body without parasitic torques. The lower part of the bush was machined to form the mating surface of the 
spherical bearing. This bearing system allows accurate measurements of the bush torque to be made.

The feeding pressure is regulated by a precision restrictor valve and monitored by a Bourdon pressure gauge, with an error of $\pm 0.004 \mathrm{MPa}$, located at the oil distribution collector. The feeding temperature is regulated via a cryothermostat serving the oil tank. Its value is monitored by a thermocouple located in the oil distribution collector and is kept within a range of $\pm 1^{\circ} \mathrm{C}$ from the set point.

The measurements were always made under a steady-state regime. In order to achieve this, start-up times were set for thermal stabilization. Between tests, parameters such as temperature and flow-rate were monitored until stabilization occurred.

The oil flow was measured by an electric pulse gear flow meter attached to the data acquisition system, with an accuracy of $\pm 0.05 \mathrm{l} / \mathrm{min}$. The temperature field was monitored by type $\mathrm{K}$ thermocouples inserted in $0.5 \mathrm{~mm}$ metal sleeves and attached to a data acquisition system with signal conditioning. The accuracy of the measured values is $\pm 0.7^{\circ} \mathrm{C}$. The temperature at the oil-bush interface was measured at the locations depicted in Fig. 3. The sleeved thermocouples are placed inside fully drilled holes. The active part of the thermocouple is flush with the inner surface of the bush. In addition, thermocouples were positioned so as to measure the oil outlet temperature, the ambient temperature (environment temperature around the bearing) and the bush body temperature at two different locations. The temperature at the oil-shaft interface was also measured at three different points by type $\mathrm{K}$ thermocouples connected to the system by a rotary joint.

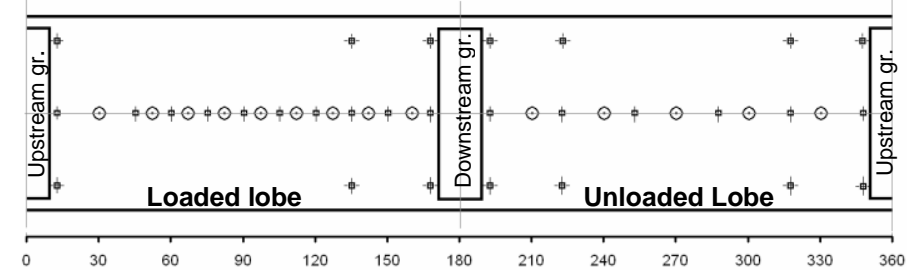

Fig. 3 - Angular location of the thermocouples ( 曲) and pressure holes $(\odot)$ at the inner surface of the bush.

The hydrodynamic pressure profile was measured by high precision Bourdon pressure gauges attached via manifold valves to a series of $1 \mathrm{~mm}$ holes drilled in the bush mid-plane, as detailed in Fig. 3. The measured pressure was generally greater than $30 \%$ of the total range of each pressure gauge. The measuring uncertainties are $\pm 0.01 \mathrm{MPa}$ for pressure values lower than $0.1 \mathrm{MPa}$ and $\pm 3 \%$ for higher values.

The relative shaft position was obtained with the help of two pairs of Eddy Current proximity probes located at $\pm 45^{\circ}$ to the load line, on both sides of the bearing. The sensitivity of each sensor ranges from 7 to $7.63 \mathrm{mV} / \mu \mathrm{m}$. The accuracy of the displacement measurements was $\pm 5 \mu \mathrm{m}$. These measurements were corrected taking into consideration the estimated thermal deformation of the system. The locus of the shaft center is relative to a reference test where the absolute position of the shaft has been obtained from a theoretical model presented by Costa et al. [13] adapted for twin groove bearings. A specific reference test was used for each rotational speed. Therefore, the calculated position of the shaft centerline in relation to the bush centerline should be looked as relative to the reference position chosen for that specific rotational speed.

A $x-y$ system with origin at the bush center was defined as shown in Fig. 4. The axes are coincident with the two directions of measurement.

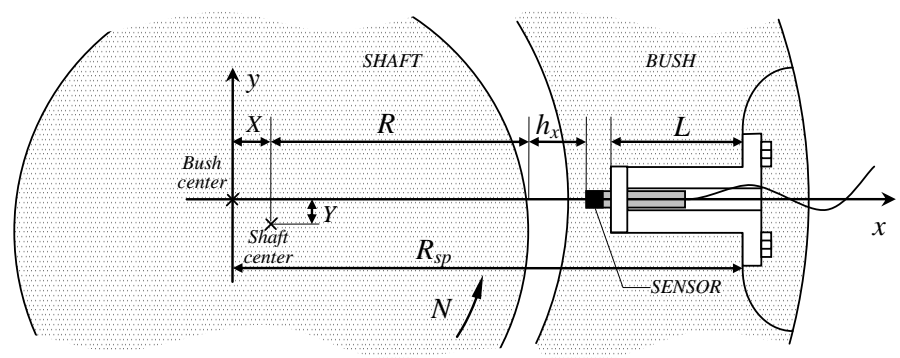

Fig. 4 - Detail of the proximity probe system

The coordinates of the reference position, $\left(X_{r e f}, Y_{\text {ref }}\right)$, are known. The measurements of the sensors at this position are $h_{x \text { ref }}$ and $h_{y \text { ref }}$. Therefore, for the $x$ direction, the following expression applies:

$$
X-X_{\text {ref }}=\Delta X=-\left(h_{x c}-h_{x \text { ref }}\right)
$$

Where $h_{x c}$ is the corrected value of $h_{x}$, taking into account the differences in geometry caused by thermal deformation. Without considering thermal deformation, $h_{x c}$ equals the proximity probe response, $h_{x}$.

$$
\begin{aligned}
h_{x c} & =h_{x}+\left[\left(R-R_{r e f}\right)-\left(R_{s p}-R_{s p r e f}\right)+\left(L-L_{r e f}\right)\right]= \\
& =h_{x}+\Delta R-\Delta R_{s p}+\Delta L
\end{aligned}
$$

Being $R$ the shaft radius, $L$, the length of the sensor support and $R_{s p}$ the bush radius at the location where the sensor support is attached. Finally,

$$
\Delta X=-\Delta h_{X}-\Delta R+\Delta R_{s p}-\Delta L
$$

Where

$$
\Delta h_{x}=h_{x}-h_{x r e f}
$$

In order to estimate thermal deformation, an effective temperature was calculated for each component, based on thermocouple information. Boncompain et al. [14] demonstrated numerically that about $10 \%$ of the heat generated inside the bearing is removed by conduction through the shaft. This means that the temperature gradient in the shaft is small; for this reason, the average shaft temperature has to be a 
weighted average of the measured oil-shaft interface temperature (90\%) and the supply temperature $(10 \%)$, the oilshaft interface temperature corresponding to the maximum shaft temperature. Sensor support temperatures were measured directly by dedicated thermocouples. The effective bush temperature was obtained from a weighted average of the mean inner surface temperature $(70 \%)$ and the temperature given by a thermocouple located inside the bush, $2 \mathrm{~mm}$ from its outer surface $(30 \%)$. It was observed that the estimate of the thermal deformation is affected by the method of calculation adopted.

A static sensor was used to measure the torque applied to the bush, $T_{b}$. Power loss, $P$, was obtained from the following formula:

$$
P=\left[T_{b}+e \cdot W \cdot \sin (\varphi)\right] \cdot \Omega
$$

Where $e$ is the shaft eccentricity, $W$ is the applied load, $\varphi$ is the attitude angle and $\Omega$ is the angular velocity. Repeatability of the tests was checked. Each test was repeated at least once on a different occasion. Differences in maximum pressure and maximum temperature were, respectively, less than $\pm 0.01 \mathrm{MPa}$ and $\pm 1^{\circ} \mathrm{C}$ in most cases. The accuracy of bush torque measurements was found to be significantly affected by the instrumentation attached to the bearing (thermocouple wires, proximity probe wires, oil supply and oil measurement hoses), making it difficult to set the zero of the scale. Sometimes measurements between corresponding tests yielded differences as high as $0.5 \mathrm{~N} \cdot \mathrm{m}$. The values obtained should therefore be regarded with caution.

The geometric parameters and operating conditions, as well as lubricant properties, are presented in Table 1.

Table 1 - Bearing geometry, operating conditions, and lubricant properties

\begin{tabular}{lcll}
\hline Parameters & & Units & Value/Span \\
\hline Rotational speed & $N$ & $\mathrm{rpm}$ & $1000,3000,4000$ \\
Applied load & $W$ & $\mathrm{kN}$ & 2,10 \\
Supply pressure & $P_{f}$ & $\mathrm{kPa}$ & $70,140,210$ \\
Supply temperature & $T_{f}$ & ${ }^{\circ} \mathrm{C}$ & $35,40,50$ \\
Bush inner diameter (nominal) & $d$ & $\mathrm{~mm}$ & 100 \\
Bush outer diameter (including & $D$ & $\mathrm{~mm}$ & 200 \\
sleeve) & & & \\
Bush length & $b$ & $\mathrm{~mm}$ & 80 \\
Groove length & $a$ & $\mathrm{~mm}$ & 70 \\
Circumferential extension of & $w$ & $\mathrm{~mm}$ & 16 \\
each groove & & & \\
Diametral clearance $\left(20^{\circ} \mathrm{C}\right)$ & $C_{d}$ & $\mu \mathrm{m}$ & 171 \\
Lubricant viscosity $\left(40^{\circ} \mathrm{C}\right)$ & $\mu_{40}$ & $\mathrm{~Pa} . \mathrm{s}$ & 0.0293 \\
Lubricant viscosity $\left(70^{\circ} \mathrm{C}\right)$ & $\mu_{70}$ & $\mathrm{~Pa} . \mathrm{s}$ & 0.0111 \\
Lubricant thermal conductivity & $K_{l}$ & $\mathrm{~W} / \mathrm{mK}$ & 0.13 \\
Bush thermal conductivity & $K_{b}$ & $\mathrm{~W} / \mathrm{mK}$ & 50 \\
Lubricant specific mass & $\rho$ & $\mathrm{kg} / \mathrm{m}^{3}$ & 870 \\
Lubricant specific heat & $C_{p}$ & $\mathrm{~J} / \mathrm{kgK}$ & 2000 \\
Ambient temperature & $T_{a m b}$ & ${ }^{\circ} \mathrm{C}$ & 30 to 55 \\
(inside protection box) & & & \\
\hline
\end{tabular}

\section{RESULTS AND DISCUSSION}

Results concerning the influence of the feeding pressure and feeding temperature on bearing performance for different sets of working conditions will be presented and analyzed. Tests were carried out for two values of applied load: $2 \mathrm{kN}$ and
$10 \mathrm{kN}$. The former value is very low for the bearing under consideration, but is of theoretical interest. Three different values of the shaft rotation speed were considered: 1000, 3000 and 4000rpm. Three different values of both the feeding pressure and feeding temperature were tested: 70, $140,210 \mathrm{kPa}$ and $35,40,50^{\circ} \mathrm{C}$, respectively. In each case, the measured parameters were: hydrodynamic pressure and temperature fields, oil flow rate, bush torque, and position of the shaft center relative to the bush. The power losses in the bearing were deduced from the measured torque.

\subsection{Effect of changes in feeding pressure}

\section{Hydrodynamic pressure distribution and position of shaft center}

Figure 5 represents the hydrodynamically generated pressure profile at the mid-plane of the bearing. This was obtained from tests at two different feeding pressures (70 and $210 \mathrm{kPa})$ and under two different loads (2 and $10 \mathrm{kN})$. The values of maximum pressure are also given for the high loaded case in Fig. 5(c). The angle origin is located at the center of the upstream groove: the two feeding grooves here are called the upstream and downstream grooves, depending on whether the groove is located upstream or downstream of the minimum film thickness. The lower and upper halves of the bush here are called the loaded and the unloaded lobes of the bush, reflecting the different contribution of the hydrodynamic pressure field in the two lobes.
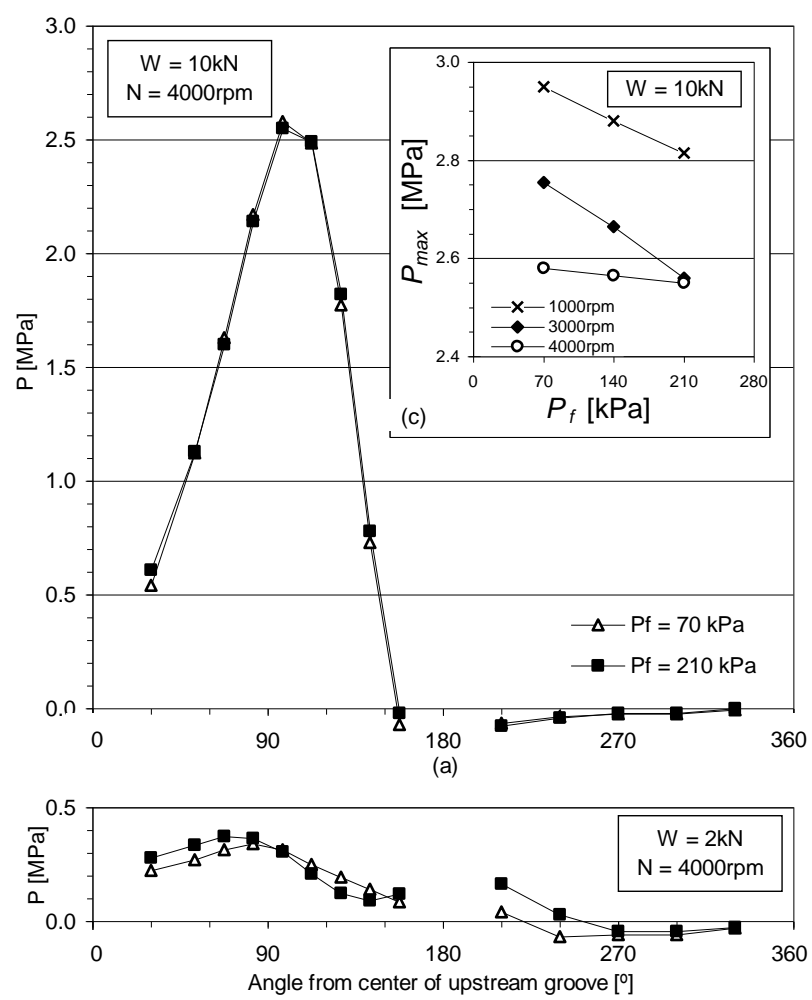

(b)

Fig. 5 - Pressure profiles for (a) $10 \mathrm{kN}, 4000 \mathrm{rpm}$ tests, (b) $2 \mathrm{kN}$, 4000rpm tests, and (c) maximum pressure values $\left(T_{f}=40^{\circ} \mathrm{C}\right)$. 
In Fig. 5 it can be seen that the pressure build-up at the loaded lobe is followed by the rupture zone where cavitation takes place. Under high load (10kN, Fig. 5(a)) the pressure starts at a negative (sub-ambient) value in the unloaded lobe, gradually reaching zero. Similar pressure profiles have been obtained by Lund and Tonnesen [6]. Under low load (2kN, Fig. $5(b))$ the pressure is still positive after the downstream groove. This is so because the film rupture takes place further downstream due to the lower eccentricity. It can also be observed that an increase in supply pressure further delays the film rupture.

The differences between pressure profiles for different feeding pressures are small, but it can be noted from Fig. 5(c), that for the tests with a load of $10 \mathrm{kN}$, the maximum pressure decreases with the increase in both feeding pressure and rotational speed. This is in good agreement with Fig. 6, where it can be observed that the eccentricity decreases and the attitude angle increases with rises in value of those parameters. This means that the load capacity of the bearing has improved. Under these conditions, lower pressure peaks and wider positive pressure zones generally occur. Reasons for the increase in load capacity with feeding pressure can be related to the hydrostatic lift caused by the high supply pressure. The extension of the continuous film zone, caused by the increase in the amount of oil, also contributes to this phenomenon.

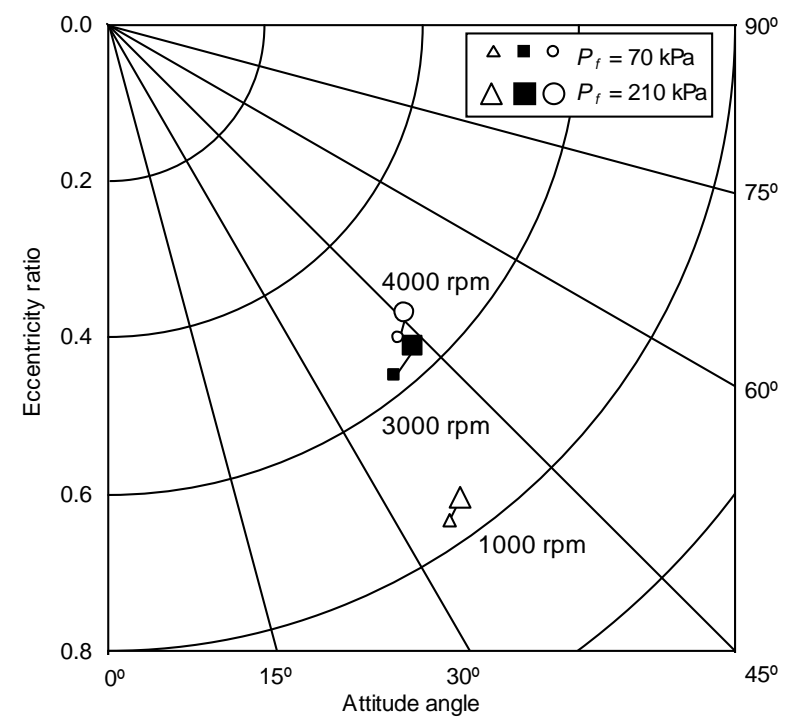

Fig. 6 - Locus of the shaft center in relation to the bush center $\left(\mathrm{W}=10 \mathrm{kN} ; T_{f}=40^{\circ} \mathrm{C}\right)$.

For low loads $(2 \mathrm{kN})$, the rise in feeding pressure caused a wider extension of the continuous film associated with a wider zone of positive pressure at the unloaded lobe (Fig. 5(b)). This causes an increase in power loss that can be confirmed in Fig. 7. Under high loads (10kN, Fig. 7(b)), the power loss did not change significantly with the increase in supply pressure. A reason for this may be the fact that the full film region does not seem to change significantly with the increase in supply pressure, as seen in Fig. 5(a).

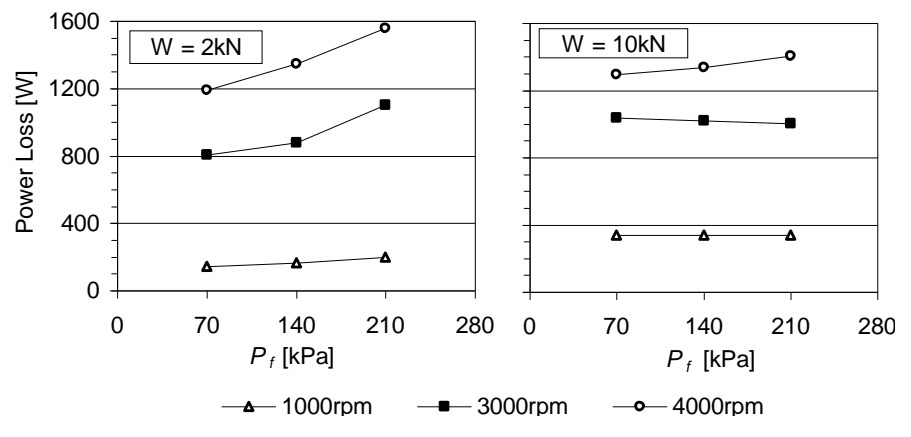

(a)

(b)

Fig. 7- Influence of speed and supply pressure on power loss for (a) $\mathrm{W}=2 \mathrm{kN}$, (b) $\mathrm{W}=10 \mathrm{kN}\left(T_{f}=40^{\circ} \mathrm{C}\right)$

\section{Oil flow rate}

Figure 8 shows the significant increase in oil flow rate with increasing feeding pressure. The same tendency is observed for increasing rotational speed (increase in the Couette effect) and applied load (increase in pressure gradients which promote oil leakage and renewal). The largest relative change in the oil flow rate is obtained using the lowest rotational speed (1000rpm), and it increases by $104 \%$ when the supply pressure is increased from 70 to $210 \mathrm{kPa}$.

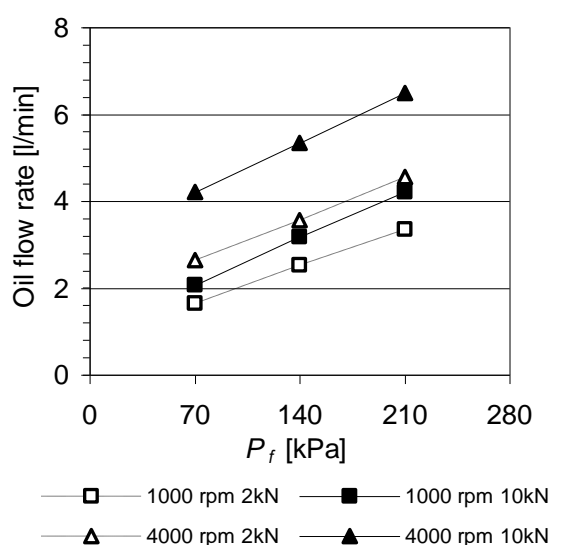

Fig. 8 - Influence of supply pressure on oil flow rate for variable rotational speed and applied load $\left(T_{f}=40^{\circ} \mathrm{C}\right)$

\section{Temperature distribution}

Figure 9 shows the temperature profiles at the mid-plane of the bush inner surface for two different values of applied load and feeding pressure.

For the lowest load value (2kN, Fig. 9a), the maximum temperature occurs in the unloaded lobe. In this case there is a significant temperature fall across the upstream groove $\left(10.2^{\circ} \mathrm{C}\right.$ and $12.0^{\circ} \mathrm{C}$ for feeding pressures of $70 \mathrm{kPa}$ and $210 \mathrm{kPa}$, respectively), while the cooling effect of the downstream groove is only significant if the feeding pressure is high $\left(3.6^{\circ} \mathrm{C}\right.$ for $210 \mathrm{kPa})$. For the highest applied load (10kN, Fig. 9b) the maximum temperature value is located in the loaded lobe. Here the temperature drop across the upstream groove gets weaker $\left(4.6^{\circ} \mathrm{C}\right.$ and $3.8^{\circ} \mathrm{C}$ for feeding pressures of $70 \mathrm{kPa}$ and $210 \mathrm{kPa}$, 
respectively), while the cooling effect of the downstream groove becomes more effective. The high pressure gradient in the loaded lobe promotes an increase in oil flow outwards, causing an increase in oil renewal at the downstream groove even at low feeding pressures. The temperature fall across this groove was about $10.5^{\circ} \mathrm{C}$ independently of the value of feeding pressure. Under low loads, however, much of the oil is recirculated, so the downstream groove contributes only poorly to the cooling of the bearing unless the feeding pressure is high. Therefore, the increase in feeding pressure had a positive effect in terms of lowering the maximum temperature of the bearing only under low load conditions. Figure 10(a) shows that the strongest decrease in maximum temperature $\left(3.5^{\circ} \mathrm{C}\right)$ occurs with a rotational speed of 4000rpm. The same tendency was observed with the shaft surface temperature, as depicted in Fig. 10(b). However, the oil outlet temperature always decreased with the increase in feeding pressure, as shown in Fig.10(c). The maximum decrease $\left(4.7^{\circ} \mathrm{C}\right)$ is obtained for the high speed / low load conditions.
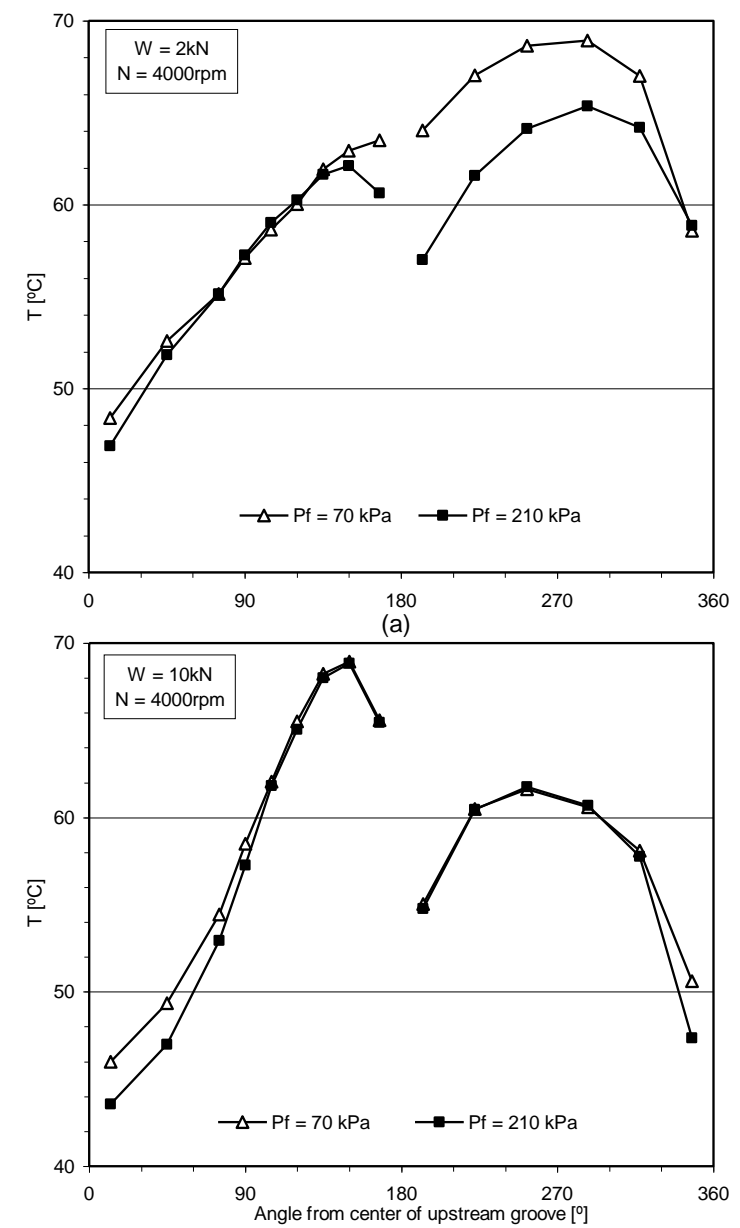

(b)

Fig. 9 - Influence of the supply pressure on the temperature profile at the mid-plane of the bush-film interface, for a load of (a) $2 \mathrm{kN}$ and (b) $10 \mathrm{kN}\left(\mathrm{N}=4000 \mathrm{rpm} ; T_{f}=40^{\circ} \mathrm{C}\right)$
Under low loads and low feeding pressures, the inner bush surface temperature profile approaches that of a bearing with a single axial groove located at $90^{\circ}$ in relation to the loading line.

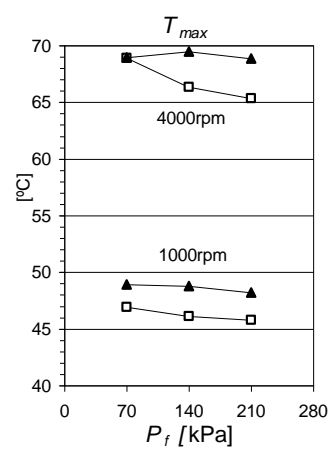

(a)

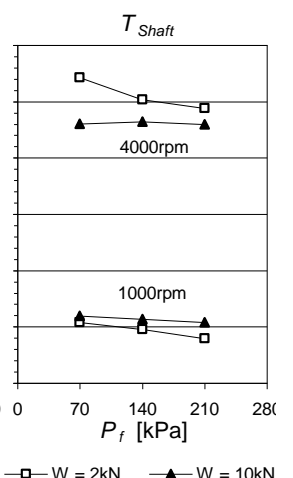

(b)

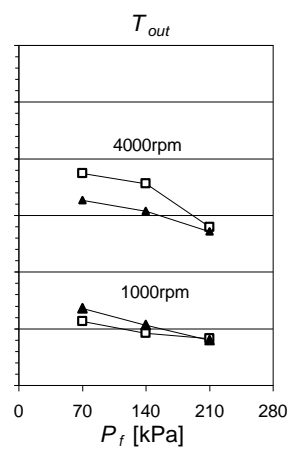

(c)
Fig. 10 - Influence of the oil supply pressure on (a) the maximum temperature at the bush-film interface, (b) the mean shaft-film interface temperature and (c) the oil outlet temperature $\left(T_{f}=40^{\circ} \mathrm{C}\right)$.

Results in the literature [3] for this kind of bearing showed that the location of maximum temperature tends to move towards the upstream direction as load increases. For sufficiently high loads, the temperature peak will eventually occur before the downstream groove, as observed in Fig. 9(b) for the $10 \mathrm{kN}$ tests. This explains why, under high applied loads $(10 \mathrm{kN})$, the increase in feeding pressure does not seem to significantly affect the maximum temperature at the bush and shaft interfaces. The main differences between $10 \mathrm{kN}$ tests lie in the upstream groove region. On the other hand, under low load $(2 \mathrm{kN})$, the increase in feeding pressure lowers the temperature both before and after the downstream groove, as is shown in Fig. 9(a).

\subsection{Influence of changes in feeding temperature.}

\section{Hydrodynamic pressure distribution and position of shaft center}

Hydrodynamic pressure profiles at the mid-plane of the bush inner surface are presented in Fig. 11, for a load of 10kN and two values of rotational speed (1000 and $4000 \mathrm{rpm})$ and feeding temperature $\left(35\right.$ and $\left.50^{\circ} \mathrm{C}\right)$. 

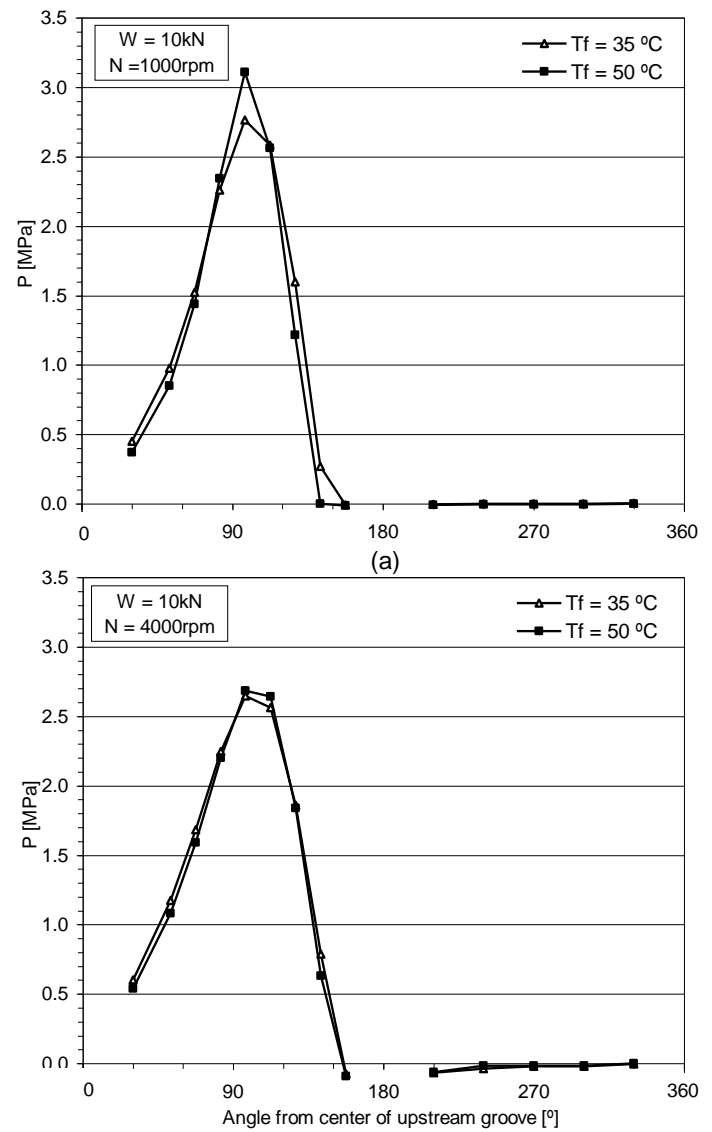

(b)

Fig. 11 - Influence of the supply temperature on the pressure profiles at the mid-plane of the bearing for (a) $N=1000 \mathrm{rpm}$ and (b) $\mathrm{N}=4000 \mathrm{rpm}\left(\mathrm{W}=10 \mathrm{kN} ; P_{f}=140 \mathrm{kPa}\right)$

One can note that the increase of feeding temperature yields greater pressure peaks and causes the pressure build-up zones to have slightly smaller angular extent, this being more pronounced at low rotational speed. This is associated with a decrease in the bearing load carrying capacity (higher operating eccentricity) due to increasing bearing temperature and subsequent lower viscosity, as is confirmed in Fig. 12.

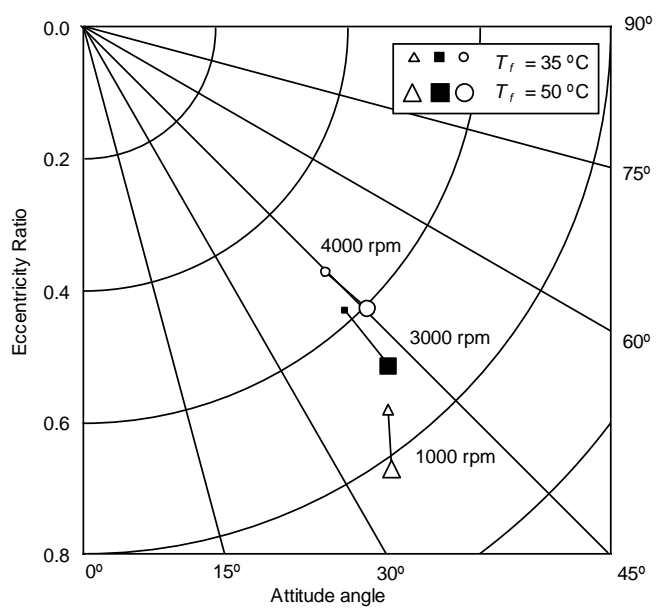

Fig. 12 - Locus of the shaft center in relation to the bush center (W $\left.=10 \mathrm{kN} ; P_{f}=140 \mathrm{kPa}\right)$.

\section{Oil flow rate and Power loss}

Figure 13 represents oil flow rate evolution with changes in feeding temperature for different values of rotational speed (1000 and 4000rpm) and applied load (2 and 10kN). Increasing applied load promotes oil renewal as a consequence of the greater pressure gradients present in the lubricant film. Similarly, the increase in feeding temperature causes a drop in oil viscosity, thus increasing flow rate. The increase in oil flow rate varies from 1.0 to $1.3 \mathrm{l} / \mathrm{min}$ when the temperature increases from $30^{\circ} \mathrm{C}$ to $50^{\circ} \mathrm{C}$, depending on operating conditions.

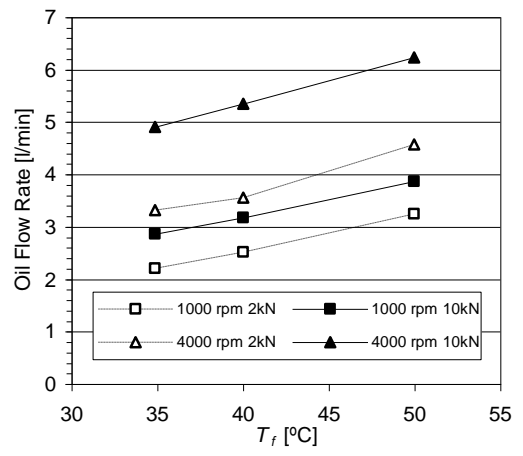

Fig. 13 - Influence of oil supply temperature in oil flow rate $\left(P_{f}=140 \mathrm{kPa}\right)$.

Power loss decreases with increasing feeding temperature, as shown in Fig. 14(a). This is due to the decrease of oil viscosity in the film, thus reducing lubricant shear rate. Under high loads, however, the increase of feeding temperature also increases significantly the eccentricity ratio (recall Fig. 12). This effect, which causes the appearance of large velocity gradients through the film thickness, seems to counterbalance the above effect and leads to the power loss stability with variations in feeding temperature. When the supply temperature increases from 35 to $50^{\circ} \mathrm{C}$ the decrease in power loss varies from 18 to $55 \%$ for the $2 \mathrm{kN}$ case and from 0 to $9 \%$ for the 10 $\mathrm{kN}$, depending on the rotational speed.

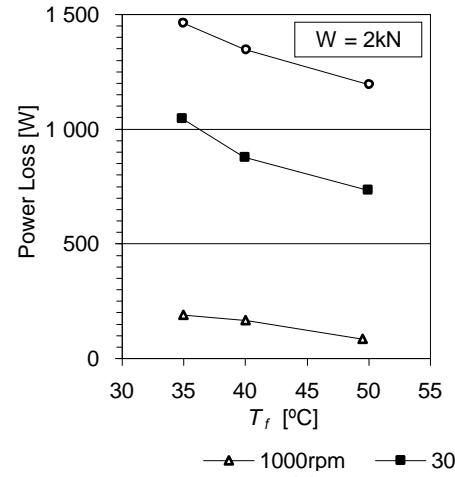

(a)

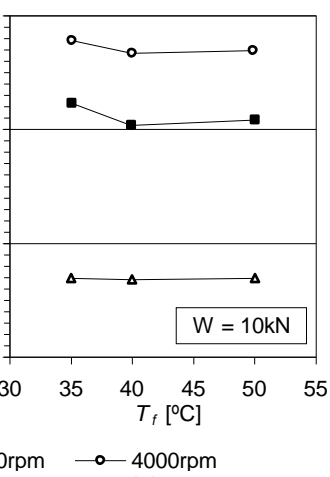

(b)
Fig. 14 - Influence of oil supply temperature on power loss for an applied load of (a) $2 \mathrm{kN}$ and (b) $10 \mathrm{kN}\left(P_{f}=140 \mathrm{kPa}\right)$

\section{Temperature distribution}

Figure 15 shows the temperature profiles at the mid-plane of the bush-film interface for a set of operating conditions and feeding temperatures. 


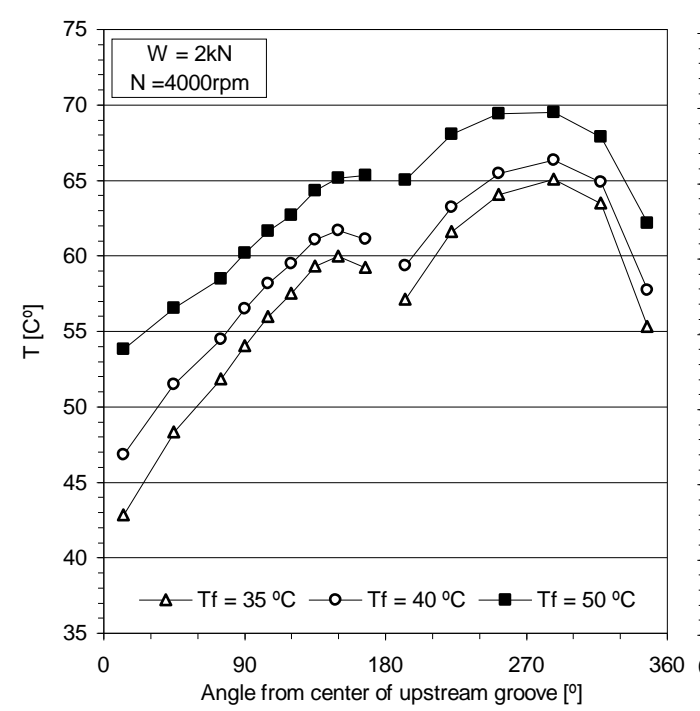

(a)

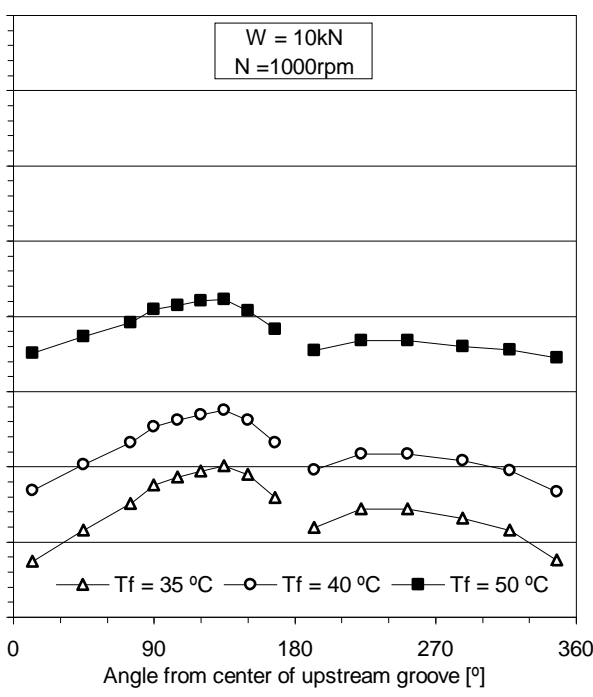

(b)

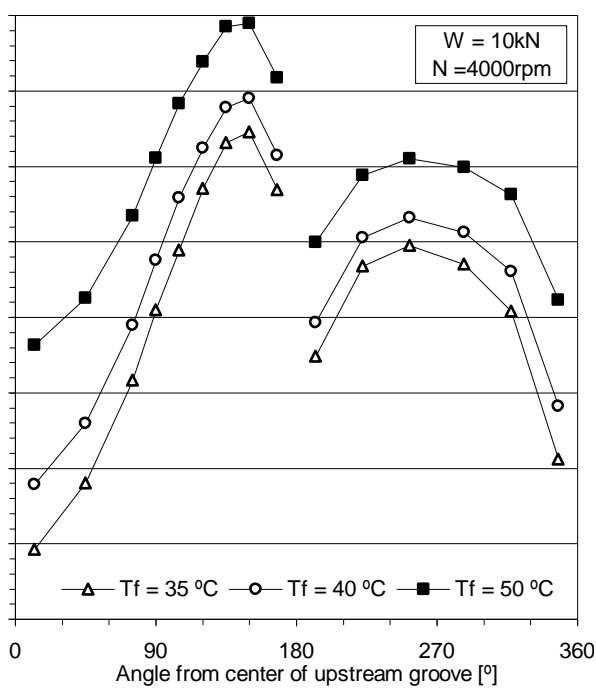

(c)

Fig. 15 - Temperature profiles at the mid-plane of the bush-film interface for three different supply temperatures with (a) $\mathrm{W}=\mathbf{2 k N}$, $\mathrm{N}=4000 \mathrm{rpm}$, (b) $\mathrm{W}=10 \mathrm{kN}, \mathrm{N}=1000 \mathrm{rpm},(\mathrm{c}) \mathrm{W}=10 \mathrm{kN}, \mathrm{N}=4000 \mathrm{rpm}\left(P_{f}=140 \mathrm{kPa}\right)$

The results for lightly-loaded conditions (low load and high velocity) are depicted in Fig. 15(a). The general temperature profile obtained has already been discussed in association with Fig. 8. Figures $15(\mathrm{~b})$ and 15(c) show the temperature profiles for a low (1000rpm) and a high (4000rpm) rotational speed, the applied load here being $10 \mathrm{kN}$. The temperature profiles exhibit the same trend of variation for all values of feed temperature tested.

Increasing feeding temperature resulted in the increase of the bush-film interface temperature. However, the increase in maximum bush-film interface temperature was always less than the corresponding increase in oil feed temperature. For $\mathrm{N}=$ 4000rpm (Fig. 15(c)), the increase of the former was between $30 \%$ (low load) and 50\% (high load) of the increase recorded for the feeding temperature. Increasing rotational speed caused a general increase in bush-film interface temperature, due to the increase in energy dissipation.

It can also be noted that, as the feeding temperature increased, the temperature decrease across the groove zones was smaller, because of the hotter feeding oil entering the grooves.

Comparing the three figures, it can be observed that the higher the eccentricity ratio, the further upstream the maximum temperature occurs. This could be due to the fact that, as eccentricity increases, the film becomes more divergent. This promotes the appearance of cavitation phenomena further upstream (compare the pressure profiles in Fig. 11(a) and 11(b), and the corresponding eccentricity ratios in Fig. 12). The heat generated in cavitated films is very low compared with the heat generated in continuous lubricant film, as it contains as it contains gas bubbles which have low viscosity.

The temperature of the shaft-film interface $\left(T_{\text {shaft }}\right)$ presented in Fig. 16(a) and the oil outlet temperature $\left(T_{\text {out }}\right)$ presented on Fig. 16(b) are significantly affected by shaft speed. $T_{\text {shaft }}$ is only slightly affected by load, while the effect of this parameter on $T_{\text {out }}$ is only significant at low values of the feeding temperature and high rotational speed. At low speed $(\mathrm{N}=1000 \mathrm{rpm}) T_{\text {shaft }}$ is very close to $T_{\text {out }}$. At high speed (N=4000rpm), $T_{\text {shaft }}$ is significantly higher than $T_{\text {out }}$.
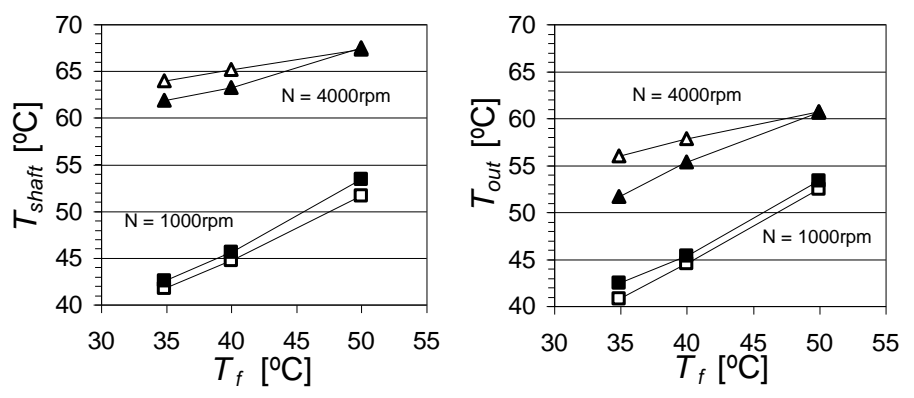

$\square-1000 \mathrm{rpm} 2 \mathrm{kN} \longrightarrow 1000 \mathrm{rpm} 10 \mathrm{kN} \backsim \Delta-4000 \mathrm{rpm} 2 \mathrm{kN} \smile 4000 \mathrm{rpm} 1$

(a)

(b)

Fig. 16 - Influence of oil supply temperature on (a) the mean shaftfilm interface temperature and (b) the oil outlet temperature $\left(P_{f}=140 \mathrm{kPa}\right)$

Comparing the values of $T_{\text {shaft }}$ with the corresponding temperature profiles, presented earlier in Fig. 15, it can be noted that the shaft temperature is very close to the maximum temperature for low load tests $(2 \mathrm{kN}$, Fig $15(\mathrm{a}))$. In high load tests $(10 \mathrm{kN}$, Fig 15 (b) and $15(\mathrm{c}))$ however, $T_{\text {shaft }}$ is 5 to $8^{\circ} \mathrm{C}$ below the maximum temperature and always above the peak temperature achieved at the unloaded lobe. This difference could be due to the fact that in low load tests the shaft is almost concentric with the bush while, under high load tests, there is a highly convergent-divergent lubricant film. This yields more localized heat generation near the region of minimum film 
thickness. Under low loads however, the heat generation is less concentrated, and there is a low rate of oil renewal. Under these circumstances a greater thermal uniformity is expected, with $T_{\max }$ being closer to the value of $T_{\text {shaft }}$.

\section{CONCLUSIONS}

Experimental investigations of the influence of the feeding temperature and pressure on the steady-state performance of a two-grooved plain journal bearing were carried out for a set of operating conditions. Results concerning the temperature and pressure fields inside the bearing, oil flow rate, power loss, and the position of shaft center have been presented above and discussed. The following conclusions can be drawn:

i) Increasing supply temperature increases oil flow rate, shaft eccentricity and maximum temperature. The observed increase in maximum temperature is significantly lower than the corresponding increase in supply temperature.

ii) Shaft temperature and oil outlet temperature were mainly affected by feeding temperature and rotational speed. At high shaft speeds, the mean shaft temperature is significantly higher than the outlet temperature.

iii) The increase in feeding pressure yields an increase in oil flow rate, a decrease in oil outlet temperature and a slight increase in the attitude angle and minimum film thickness.

iv) Under low applied loads the cooling effect of the upstream groove is apparent, while the cooling effect of the downstream groove is only significant at high supply pressures. Maximum temperature occurs in the unloaded lobe of the bearing, being only slightly higher than the mean shaft surface temperature.

v) Under high applied loads the cooling effect of the upstream groove becomes weaker, while the cooling effect of the downstream groove is significant no matter the value of the supply pressure. Maximum temperature occurs at the loaded lobe of the bearing, and was found to be 4 to $8^{\circ} \mathrm{C}$ higher than the shaft surface temperature for the conditions tested.

\section{ACKNOWLEDGEMENTS}

The present work was undertaken under the project POCTI/39202/EME/2001, funded by FCT - Fundação para a Ciência $e$ a Tecnologia (Portugal) and the European Union fund FEDER. The work has been carried out at the Laboratoire de Mécanique des Solides, URM CNRS 6610, University of Poitiers (France). The authors greatly acknowledge the support of these institutions.

\section{REFERENCES}

[1] Dowson, D., Hudson, J., Hunter, B., and March, C., 1966-67, "An Experimental Investigation of the Thermal Equilibrium of Steadily Loaded Journal Bearings," Proc. Inst. Mech. Eng., Vol. 101, Part 3B, pp. 70-80.

[2] Majumdar, C. B., and Saha, A. K., 1974, "Temperature Distribution in Oil Journal Bearings," Wear, 28, pp. 259266.
[3] Mitsui, J., Hori, Y., and Tanaka, M., 1983, "Thermohydrodynamic Analysis of Cooling Effect of Supply Oil in Circular Journal Bearings" ASME Journal of Tribology, 105, pp. 414-421

[4] Syverud, T., and Tanaka, M., 1997, "Experimental Investigation of the Effect of Shaft Heating and Cooling on Single Bore Journal Bearing," Wear, 207, pp. 112117.

[5] Costa L., Fillon, M., Miranda, A. S., and Claro, J. C. P., 2000, "An experimental Investigation of the Effect of Groove Location and Supply Pressure on the THD Performance of a Steadily Loaded Journal Bearing”, ASME Journal of Tribology, 122, pp 227-231.

[6] Lund, J. W., and Tonnesen, J., 1984, "An Approximate Analysis of the Temperature Conditions in a Journal Bearing. Part II: Application", ASME Journal of Tribology, 106, pp. 237-245.

[7] Claro, J. C. P., 1994, "Reformulação do Método de Cálculo de Chumaceiras Radiais Hidrodinâmicas Análise do Desempenho, Considerando as Condições de Alimentação", PhD Thesis, Universidade do Minho, Guimarães (Portugal).

[8] Gethin D. T., and El-Deihi, M. K. I., 1990, "Thermal Behavior of a Twin Axial Groove Bearing Under Varying Loading Direction", Proc. ImechE, 204, pp. 77-90.

[9] Fitzgerald, M. K., and Neal, P. B., 1992, “Temperature Distributions and Heat Transfer in Journal Bearings", ASME Journal of Tribology, 114, pp. 122-130.

[10] Ma, M. T., and Taylor, C. M., 1995, "Effects of Oil Feed Temperature on the Performance of an Elliptical Bore Bearing", Lubricants and Lubrication - Proceedings of the $21^{\text {st }}$ Leeds-Lyon Symposium on Tribology, Institute of Tribology, University of Leeds, U.K., $6^{\text {th }}-9^{\text {th }}$ September 1994, pp 143-151.

[11] Ferron, J., Frêne, J., and Boncompain, R., 1983, "A Study of the Thermohydrodynamic Performance of a Plain Journal Bearing. Comparison Between Theory and Experiments," ASME J. Lubr. Technol., 105, pp. 422428.

[12] Bouyer, J., and Fillon, M., 2002 "An Experimental Analysis of Misalignment Effects on Hydrodynamic Plain Journal Bearing Performances", ASME Journal of Tribology, 124, pp. 313-319.

[13] Costa, L., Miranda, A. S., Fillon, M., and Claro, J. C. P., 2003, "An Analysis of the Influence of Oil Supply Conditions on the Thermohydrodynamic Performance of a Single Groove Journal Bearing”, Proc. Inst. Mech. Engs., Part J: Journal of Engineering Tribology, 217, pp. 133-144.

[14] Boncompain, R., and Frêne, J., 1980, "Thermohydrodynamic Analysis of a Finite Journal Bearing Static and Dynamic Characteristic", Proc. of the 6th Leeds-Lyon Symposium - Thermal effect in Tribology, Mech. Eng.Publi. Ltd, pp.33-41. 


\section{LISTING OF FIGURE AND TABLE CAPTIONS IN ORDER OF APPEARANCE}

Fig. 1 - Test rig

Fig. 2 -3D drawing of the inner part of the bush

Fig. 3 - Angular location of the thermocouples ( $)$ and pressure holes $(\odot)$ at the inner surface of the bush.

Fig. 4 - Detail of the proximity probe system

Table 1 - Bearing geometry, operating conditions, and lubricant properties

Fig. 5 - Pressure profiles for (a) $10 \mathrm{kN}, 4000 \mathrm{rpm}$ tests, (b) $2 \mathrm{kN}, 4000 \mathrm{rpm}$ tests, and (c) maximum pressure values $\left(\mathrm{T}_{\mathrm{f}}=40^{\circ} \mathrm{C}\right)$.

Fig. 6 - Locus of the shaft center in relation to the bush center $\left(\mathrm{W}=10 \mathrm{kN} ; \mathrm{Tf}=40^{\circ} \mathrm{C}\right)$.

Fig. 7- Influence of speed and supply pressure on power loss for (a) $\mathrm{W}=2 \mathrm{kN}$, (b) $\mathrm{W}=10 \mathrm{kN}\left(\mathrm{T}_{\mathrm{f}}=40^{\circ} \mathrm{C}\right.$ )

Fig. 8 - Influence of supply pressure on oil flow rate for variable rotational speed and applied load $\left(\mathrm{T}_{\mathrm{f}}=40^{\circ} \mathrm{C}\right)$

Fig. 9 - Influence of the supply pressure on the temperature profile at the mid-plane of the bush-film interface, for a load of (a) $2 \mathrm{kN}$ and (b) $10 \mathrm{kN}\left(\mathrm{N}=4000 \mathrm{rpm} ; \mathrm{T}_{\mathrm{f}}=40^{\circ} \mathrm{C}\right)$

Fig. 10 - Influence of the oil supply pressure on (a) the maximum temperature at the bush-film interface, (b) the mean shaft-film interface temperature and (c) the oil outlet temperature $\left(\mathrm{T}_{\mathrm{f}}=40^{\circ} \mathrm{C}\right)$.

Fig. 11 - Influence of the supply temperature on the pressure profiles at the mid-plane of the bearing for (a) $\mathrm{N}=1000 \mathrm{rpm}$ and (b) $\mathrm{N}=$ $4000 \mathrm{rpm}\left(\mathrm{W}=10 \mathrm{kN} ; \mathrm{P}_{\mathrm{f}}=140 \mathrm{kPa}\right)$

Fig. 12 - Locus of the shaft center in relation to the bush center $\left(\mathrm{W}=10 \mathrm{kN} ; \mathrm{P}_{\mathrm{f}}=140 \mathrm{kPa}\right)$.

Fig. 13 - Influence of oil supply temperature in oil flow rate $\left(\mathrm{P}_{\mathrm{f}}=140 \mathrm{kPa}\right)$.

Fig. 14 - Influence of oil supply temperature on power loss for an applied load of (a) $2 \mathrm{kN}$ and (b) $10 \mathrm{kN}$ load $\left(\mathrm{P}_{\mathrm{f}}=140 \mathrm{kPa}\right)$

Fig. 15 - Temperature profiles at the mid-plane of the bush-film interface for three different supply temperatures with (a) $\mathrm{W}=2 \mathrm{kN}, \mathrm{N}$ $=4000 \mathrm{rpm},(\mathrm{b}) \mathrm{W}=10 \mathrm{kN}, \mathrm{N}=1000 \mathrm{rpm},(\mathrm{c}) \mathrm{W}=10 \mathrm{kN}, \mathrm{N}=4000 \mathrm{rpm}\left(\mathrm{P}_{\mathrm{f}}=140 \mathrm{kPa}\right)$

Fig. 16 - Influence of oil supply temperature on (a) the mean shaft-film interface temperature and (b) the oil outlet temperature $\left(\mathrm{P}_{\mathrm{f}}=\right.$ $140 \mathrm{kPa})$ 